\title{
Developing a Rigorous Measure of the Pre-School Home Mathematics Environment
}

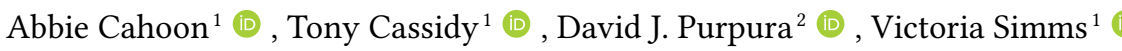 \\ [1] School of Psychology, Ulster University, Coleraine, United Kingdom. [2] Human Development and Family Studies, Purdue University, West Lafayette, IN, USA.
}

Journal of Numerical Cognition, 2021, Vol. 7(2), 172-194, https://doi.org/10.5964/jnc.6373

Received: 2019-10-07 • Accepted: 2021-01-20 • Published (VoR): 2021-07-23

Handling Editor: Wim Fias, Ghent University, Ghent, Belgium

Corresponding Author: Abbie Cahoon, School of Psychology, Ulster University, Cromore Road, Coleraine, BT52 1SA, UK. E-mail: a.cahoon@ulster.ac.uk

Supplementary Materials: Materials [see Index of Supplementary Materials]

\begin{abstract}
Children begin pre-school with varying levels of school readiness. Those children who enter pre-school with better foundational mathematics skills are more likely to succeed in school than those who do not. This initial variation in early mathematics suggests that experiences outside of the school setting, namely the home environment, may support learning and development. This study aims to systematically develop a comprehensive home mathematics environment questionnaire that reliably assesses the experiences of pre-school children (i.e., 3-5-year-olds) following recent recognised scale development and validation methods. Four studies were used to develop and validate the Pre-school Home Mathematics Questionnaire (PHMQ). Study 1 focused on 1) item generation through individual, in-depth interviews with parents of young children and 2) identifying previous questions from other home mathematics environment (HME) questionnaires to be incorporated into the PHMQ. Study 2 involved questionnaire refinement and was used to assess the psychometric properties of the new measure while addressing construct validity (i.e., factor structure and scale score reliability). Study 3 assessed content and criterion validity of the scale. Finally, Study 4 focused on construct validity through confirmatory factor analysis. Overall, the four studies demonstrate construct, content, and criterion validity. Hence, the newly developed PHMQ satisfies the American Psychological Association (APA) standards for psychometric adequacy.
\end{abstract}

\section{Keywords}

pre-school, questionnaire, home numeracy environment, home mathematics environment, construct validity, content validity, criterion validity

Children begin pre-school with varying levels of school readiness, with those children who enter pre-school with foundational mathematics and reading skills more likely to succeed in school than those who do not (Duncan et al., 2007; Watts, Duncan, Siegler, \& Davis-Kean, 2014). This initial variation in early mathematics and reading skills suggests that experiences outside of the school setting, namely the home environment, may support learning and development (Manolitsis, Georgiou, \& Tziraki, 2013; Pomerantz, Moorman, \& Litwack, 2007). Research indicates that the home learning environment (i.e., the home literacy and numeracy environment) is a significant predictor of reading and mathematics achievement (Anders et al., 2012; Melhuish et al., 2008) but also can more broadly influence children's social and behavioural development (Sylva, Melhuish, Sammons, Siraj-Blatchford, \& Taggart, 2004, 2008). School-entry mathematical skills were found to be more important in predicting later mathematical, reading and science achievement than school-entry reading skills (Claessens \& Engel, 2013), highlighting the importance of early mathematical knowledge in school readiness development. Therefore, it is essential to understand how early mathematics skills develop due to its impact on academic achievement more generally. 


\section{The Home Learning Environment}

The frequency of home learning activities has been established to have impact on child development. For example, Melhuish et al. (2013) investigated the long-term effects of different pre-school provision on child development and found that children from homes with the lowest frequency of home learning environment activities were almost three times less likely to attain Level 5 in mathematics at the end of Key Stage 2 (i.e., 11-year-olds in Northern Ireland), than children from homes with a higher frequency of home learning environment activities. Thus, it has been suggested that the frequency of home learning environment activities can diminish or benefit individual success later in life (Sénéchal \& LeFevre, 2002).

Studies that explore the nature of the home learning environment have found wide variations between families. For instance, the quality of the home learning environment is associated with the availability of educational resources, for example books and board games (Anders et al., 2012; Cankaya \& LeFevre, 2016; Gunn, Simmons, \& Kameenui, 1995; Melhuish et al., 2008; Skwarchuk, Sowinski, \& LeFevre, 2014). Previous research demonstrates that the quality of the home learning environment can be investigated either in relation to the domain of home literacy or home numeracy (Huntsinger, Jose, Larson, Balsink Krieg, \& Shaligram, 2000; Huntsinger, Jose, Liaw, \& Ching, 1997; LeFevre et al., 2009; Sénéchal \& LeFevre, 2002) or irrespective of domain (Anders et al., 2012; Melhuish et al., 2008). There is a vast amount of literature that examines the role of the home literacy environment in contrast to the emergent literature on the home numeracy environment (HNE; Burgess, Hecht, \& Lonigan, 2002; Frijters, Barron, \& Brunello, 2000; Hart, Ganley, \& Purpura, 2016; Kirby \& Hogan, 2008; Sénéchal \& LeFevre, 2002; Sénéchal, LeFevre, Thomas, \& Daley, 1998). Hence, more research is necessary to understand the impact of the HNE.

The motivation for the creation of home mathematics environment (HME) measures has been grounded in evidence that since the early home environment (i.e., during pre-school years) has been connected to children's literacy skills it is theoretically reasonable to predict that the early home environment will impact children's numeracy skills (Blevins-Knabe, 2016; LeFevre et al., 2009, 2010; Lukie, Skwarchuk, LeFevre, \& Sowinski, 2014). Accordingly, researchers have adapted questions from home literacy environment questionnaires or generated novel questions to create HME questionnaires. Alternatively, other home numeracy questionnaire measures have been based on variations of the Home Observation for Measurement in the Environment (HOME) inventory (Caldwell \& Bradley, 1984) for example, Anders et al. (2012). However, as the development of measurements should ideally be both deductive and inductive (Williamson, Karp, Dalphin, \& Gray, 1982) the current study used both rigorous approaches for questionnaire development.

\section{Inconsistent Findings in HME Research}

It is important to note that the literature on the relation between the HME and mathematical learning has produced inconsistent results, this is in stark contrast to the literature on the home literacy environment and its relation to reading outcomes (Morrison, Bachman, \& Connor, 2005). The majority of HNE studies used questionnaire based self-report measures of the frequency of home numeracy activities. Many studies have established a positive, unique impact of the frequency of HNE activities on mathematical development (Dearing et al., 2012; Kleemans, Peeters, Segers, \& Verhoeven, 2012; Manolitsis et al., 2013; Niklas \& Schneider, 2014). In contrast, some studies have found no relation between HNE and a range of mathematical skills (e.g., Blevins-Knabe, Austin, Musun, Eddy, \& Jones, 2000; Missall, Hojnoski, Caskie, \& Repasky, 2015). Typically, research indicates that socio-economic status (SES) is related to mathematical development, (Galobardes, Shaw, Lawlor, Lynch, \& Smith, 2006; Mercy \& Steelman, 1982; Sammons et al., 2004). Even when a relationship has been established, some studies have identified that after controlling for SES and parental attitudes the relationship does not persist (DeFlorio \& Beliakoff, 2015).

\section{Child Characteristics}

A recent review of published papers indicated that inconsistent findings may be attributable to differences in age of children within samples (Thompson, Napoli, \& Purpura, 2017). This narrative review indicated that HNE did not impact on mathematical outcomes of younger children (approximately 3-4-year-olds) but did moderately affect older children (approximately 5-6-year-olds). Although not specifically highlighted by the review, it is striking to note that across the 13 included studies a wide variety of questionnaire measures were administered, with some overlapping content. 


\section{Psychometric Properties}

Some researchers who have created HNE scales have not provided adequate information about item generation and refinement, scale dimensionality, scale score reliability, or validity (e.g., Kleemans et al., 2012; LeFevre et al., 2009; Melhuish et al., 2008). As few questionnaires have been developed following best practice for scale development or have been validated beyond construct validity (e.g., LeFevre et al., 2009) the inconsistent results are perhaps unsurprising.

\section{Characteristics of Content and Activities}

There are many concepts that are captured in mathematics (i.e., numeracy, spatial skills, geometry, patterning) that are not captured in every frequency of activities questionnaire in the same way. For example, geometry is covered in both Hart et al. (2016; age 3-8 years old) and Missall, Hojnoski, and Moreano (2017; age 3-5 years old) questionnaires through different questions; "Fold or cut paper to make 3D objects," "Play with legos" (Hart et al., 2016) and "Identify shapes in the everyday settings and activities," "Put shapes together to make a larger shape" (Missall et al., 2017). The wide variety of skills that are encompassed by the concept "mathematics" and the variety of ways by which these skills can be measured could be a source of inconsistence in HME literature.

Some researchers have made distinctions between different types of activities using terms interchangeably, such as indirect versus direct and informal versus formal skills, with different definitions between studies (e.g., Anderson, 1998; LeFevre et al., 2009; Skwarchuk et al., 2014). LeFevre et al. (2009) conceptualised activities as either indirect or direct. Indirect activities were defined as those that are naturally occurring tasks that communicate mathematical information incidentally, for example playing boards games with dice, setting the table or weighing while baking. Direct activities are those that are used to directly teach mathematical skills or concepts to develop child's mathematical skills, for example practicing simple sums and learning to identify number symbols. Skwarchuk et al. (2014) suggested that participating in formal practices would support the development of symbolic mathematics knowledge, while informal mathematics exposure would promote non-symbolic mathematics skills. Skwarchuk et al. (2014) found that formal home numeracy practices accounted for unique variance in children's symbolic number knowledge whereas informal exposure to games with numerical content predicted children's non-symbolic arithmetic performance, thus supporting their hypothesis. However, this hypothesised conceptual model of the HNE (Skwarchuk et al., 2014) has rarely been replicated. For example, there appears to be a differential effect of formal and informal activities on mathematical learning, with formal activities being positively related to attainment and informal activities being negatively related (Huntsinger, Jose, \& Luo, 2016). Further, Huntsinger et al. (2016) found that participating in formal mathematics activities predicted both formal (learned through explicit instruction using rules, principles, and procedures e.g., calculations both addition and subtraction) and informal (acquired outside of formal schooling e.g., concepts of relative magnitude) mathematics knowledge, whereas engaging in informal activities predicted neither. Hence, dichotomisation of home mathematics activities does not seem to reduce the inconsistences in the literature.

In addition, some studies make a distinction between basic and advanced activities (Skwarchuk, 2009). Of course, the type of content of these two types of activities varies with age, for pre-schoolers advanced activities may include multiplicative counting, whereas this may be a basic task for a child in the early primary years. These developmental changes in children's skills have perhaps led to inconsistent findings on the relationship between HNE and mathematics skills. For older children, heightened frequency of advanced activities is associated with higher level mathematical skills, and the reverse for the frequency of basic activities (Skwarchuk, 2009; Skwarchuk et al., 2014). In contrast for younger pre-schoolers (i.e., 3-years old) the reverse is true, with more basic activities, rather than advanced, associated with higher attainment (Thompson et al., 2017). Of course, these four factors can overlap, but it is important that any validated questionnaire can record and assess this breadth of home-based activities for the targeted age group. In the context of conflicting results from a growing body of studies there is a clear need to develop and validate a coherent and inclusive measure of HME which is both reliable and valid.

\section{Other Considerations}

In addition, it is uncertain that the items within currently published HME literature reflect the rapidly changing home environment of children (albeit mainly growing up in the Global West), specifically in relation to technology (OfCom, 
2013, 2016). OfCom (2016) state that there are two devices in the home that continue to be used by children: television sets $(92 \%$ for $3-4$-year olds and $96 \%$ for $5-7 \mathrm{~s}$ ) and tablets (55\% for $3-4 \mathrm{~s}$ and $67 \%$ for $5-7 \mathrm{~s})$. Thus, technology advances have potentially expanded the reach of maths learning in the home. Yet, questions about educational technology are rarely used beyond one question in HME questionnaire measures, e.g., How often did you and your child engage in the following activities? "Uses maths software" (Huntsinger et al., 2016) and "Playing counting games using child computer or arithmetic software" (Kleemans et al., 2012) and so on (e.g., Deflorio \& Beliakoff, 2015; Skwarchuk \& LeFevre, 2015). This makes it difficult to measure the extent of educational technology being used in the home and whether it makes a difference. Hence, this study aims to develop a measure that includes a variety of items regarding educational technology in relation to maths learning. This study will explore what types of items need to be included in a HME measure that reflect educational technology practices in the home environment. Through qualitative research Cahoon, Cassidy, and Simms (2017) identified that parents regularly use technology with their preschoolers to support mathematical learning. Thus, failure to include multiple questions related to technology use in HME questionnaires may lead to misrepresentation of the home environment.

The HNE has sometimes been approached as a unidimensional construct (e.g., Blevins-Knabe \& Musun-Miller, 1996; Kleemans et al., 2012) wherein all activities occurring in the home environment related to numeracy have been measured. Thus, many studies focus on the number activities and ignore other important areas such as technology and sibling interaction (Cahoon et al., 2017). Some HNE questionnaires do cover other mathematical domains such as geometry and shape (e.g., LeFevre et al., 2009). However, most HNE questionnaires use narrow terminology by using the term numeracy. It is necessary to be more consistent in communicating that both children's numerical skills and a broader range of mathematics skills (i.e., numeracy, spatial skills, geometry, patterning etc.) are being examined for their effect on the home environment (Blevins-Knabe, 2016; Hart et al., 2016), thus the term HME may be more appropriate. In this paper the terminology HME has been used when broader range of mathematics skills are discussed (including numeracy, spatial skills, geometry, patterning).

\section{Current Study}

There are many possible reasons for the inconsistent findings among HNE research; 1) the characteristics of the children participating to the studies, 2) the psychometric properties of the questionnaires that were used in previous studies and 3) the characteristics of the content and activities that the parents offer to these children. This study aims to systematically develop a comprehensive HME questionnaire that reliably assesses the experiences of pre-school children (3-5-year-olds), this new measurement tool will be referred to as the Pre-school Home Mathematics Questionnaire (PHMQ) as it involves home environment relevant dimensions beyond numeracy. The questionnaire was developed using the framework of Learning Trajectories (Clements \& Samara, 2004) reflecting the learning goals and activities that children might engage in (Simon, 1995). Most HME questionnaires have been developed and used in home environments that reflect the developed world, for example Canada. This is the first study within the UK that has created an HME questionnaire that is culturally specific, were items are not just deductive and drawn from other HME questionnaires such as Melhuish et al. (2008). Hence, the aim of the PHMQ is to develop a culturally appropriate HME questionnaire that shows good psychometric qualities for 3-5-year olds growing up in the UK. This specific age-related focus is important due to the varied nature of activities that are appropriate across development. It is of utmost importance that this new measurement instrument demonstrates strong psychometric properties (i.e., reliability and validity, Hinkin, 1998; Schoenfeldt, 1984). The creation of measurement tools should ideally be both inductive and deductive (Williamson et al., 1982), an approach unique to this current study of scale development. An advantage of using both deductive and inductive approaches to scale development is that it increases the chances of content validity in the final scale (Hinkin, 1998).

To develop and validate the dimensions of the PHMQ and produce an instrument with evidence of reliability and validity, this study has followed recent scale development and validation research processes (e.g., Hinkin, 1998; Nunes, Pretzlik, \& Ilicak, 2005). Overall, four studies are included in this paper that support the examination of construct, content, and criterion validity. The ultimate objective of this scale development and validation process is to ensure that the new PHMQ measure aligns with APA standards for psychometric adequacy (APA, 1995; Hinkin, 1998) 


\section{General Method}

Table 1 provides an overview of the processes involved in each of the four studies within this paper that ensure rigorous development and validation methods of the PHMQ. As there are four studies involved in this current paper, each study begins with an overview followed by the method and results of the study. The only study that does not follow this structure is study one which involves an overview and method only. The reason for this is because this study involves generating items based on previous interview transcripts (Cahoon et al., 2017) and it is believed all relevant information is provided for the reader to understand how the items were generated, including information provided in the Supplementary Materials of this paper (see Appendix 2, Table 1).

Table 1

PHMQ Development and Validation Procedures

\begin{tabular}{|c|c|c|}
\hline Studies & Step by Step & Details of Studies \\
\hline Study 1: Item generation & $\begin{array}{l}\text { The creation of items that assess the construct of the home } \\
\text { mathematics environment. Scale design and coding of responses } \\
\text { (e.g., Likert scales). Initial item generation; } 44 \text { inductive and } 25 \\
\text { deductive items developed. } 8 \text { home environment dimensions within } \\
\text { the Pre-school Home Mathematics Questionnaire (PHMQ): 1) } \\
\text { Parent expectations, 2) Child maths literacy, 3) Counting ability, 4) } \\
\text { Parent-child teaching methods, 5) Target child-sibling interactions, } \\
\text { 6) Frequency of maths activities scale, 7) Child's understanding of } \\
\text { numeracy, and 8) Support question. }\end{array}$ & $\begin{array}{l}\text { Parent interviews }(N=8) \text {. Parents had children aged } 37 \text { months to } \\
59 \text { months, } M_{\text {age }}=47.5 \text { months. Content analysis. }\end{array}$ \\
\hline $\begin{array}{l}\text { Study 2: Questionnaire } \\
\text { refinement }\end{array}$ & $\begin{array}{l}\text { Confirm duration and presentation of questionnaire in pre-pilot. } \\
\text { Questionnaire administration to parents/guardians. Exploratory } \\
\text { factor analysis (EFA) of the frequency of maths activities scale. } \\
\text { Questionnaire refinement (e.g., due to lack of variability in } \\
\text { responses). }\end{array}$ & $\begin{array}{l}\text { Student population pre-pilot }(N=10) \text {. Questionnaire } \\
\text { administration }(N=172) \text {. Parents/guardians had children aged } 36 \\
\text { months to } 60 \text { months, } M_{\text {age }}=46.2 \text { months. Exploratory factor } \\
\text { analysis. Questionnaire refinement. Student population re-test }(N= \\
\text { 10). }\end{array}$ \\
\hline $\begin{array}{l}\text { Study 3: Scale validation } \\
\text { (qualitative) }\end{array}$ & $\begin{array}{l}\text { Pilot PHMQ to confirm refinement of questionnaire with parents/ } \\
\text { guardians. Parent interviews for content and criterion validity. } \\
\text { Content validity-considers whether appropriate questions have } \\
\text { been asked in the PHMQ. Criterion validity-investigates contrast } \\
\text { cases of parents with very high or very low scores on each of the } \\
\text { themes within a questionnaire and compares the contrasting cases } \\
\text { to the interview responses. }\end{array}$ & $\begin{array}{l}\text { Pilot PHMQ with parents/guardians to confirm refinement }(N= \\
\text { 30). Parent interviews }(N=8) \text {. Parents/guardians had children } 36 \\
\text { months to } 49 \text { months, } M_{\text {age }}=42.8 \text { months. Content validity. } \\
\text { Criterion validity. }\end{array}$ \\
\hline $\begin{array}{l}\text { Study 4: Scale validation } \\
\text { (quantitative) }\end{array}$ & $\begin{array}{l}\text { Confirmatory factor analysis (CFA) of the frequency of maths } \\
\text { activities scale. Construct validity. Reliability. Factor loadings. }\end{array}$ & $\begin{array}{l}\text { Questionnaire administration }(N=136) \text {. Parents/guardians had } \\
\text { children } 43 \text { months to } 54 \text { months, } M_{\text {age }}=48 \text { months. Confirmatory } \\
\text { factor analysis. }\end{array}$ \\
\hline
\end{tabular}

Each study in this paper was reviewed and approved by School of Psychology Research Ethics Committee before the study commenced. Signed written consent was obtained from all participants. For each study the criteria for participation was that the parent/guardian defined themselves as the primary carer for a children of pre-school age.

\section{Study 1: An Overview}

Following construct definition, item generation (Table 1: Study 1) featured individual, in-depth interviews with eight parents with pre-school aged children (i.e., 37 to 59 months, $M_{\text {age }}=47.5$ months), using the same transcripts used in previous literature (Cahoon et al., 2017). The interviews were exploratory and aimed to gain opinions from parents on their everyday routine activities and understand the way in which parents encourage the development of early numeracy skills in the home. The six themes that were identified from the thematic analysis were; 1) numeracy environment structure, 2) frequency of number-related experiences, 3) levels of number knowledge, 4) views of technology, 5) parent-child interactions and 6) social interaction. The diversity of the themes illustrated how the HME may be 
influenced by parents' views and experiences of numeracy-related activities and children's interactions with others. For instance, 1) the numeracy environment structure theme demonstrated the types of environments that parents create for their children to learn numeracy in the home. Initially participants state that teaching mathematics should be instinctive but admitted that it is difficult to spontaneously formulate plans. Findings showed that parents may not always be cognisant when undertaking numerical activities with their child in the home and hence the HME is largely unstructured (see Cahoon et al., 2017 for more detail). Through the thematic analysis used within this paper (i.e., Cahoon et al., 2017) the theoretical foundation for the PHMQ was developed. These transcripts were then used to generate items for the PHMQ using content analysis. In addition, previous questions from other questionnaires were identified and incorporated into the PHMQ.

\section{Method}

\section{Item Generation}

Using content analysis, this inductive approach developed 44 items to create the initial PHMQ. Further, the deductive item generation method developed a base set of items that assessed the HME drawn from previous HME measures (e.g., LeFevre et al., 2009; Lukie et al., 2014; Kleemans et al., 2012; Melhuish et al., 2008) and previous parent-child interaction research, such as observational research involving parent guidance and support (e.g., Bjorklund, Hubertz, \& Reubens, 2004; Vandermaas-Peeler, Boomgarden, Finn, \& Pittard, 2012). All items were cross-referenced between those mentioned from the interviews (e.g., a numeracy activity such as counting objects) and items from other HME measures or cited in previous parent-child interaction research. Together, the deductive items $(N=25)$ were combined with the inductive items $(N=44)$ and therefore totalled to 69 items. Thirty-eight items focused on the frequency of maths activities. Additional questions investigated more nuanced factors, such as interaction with parents and siblings. It is acknowledged that there are more numeracy items than maths items at this stage. However, this would be reflective of the age group that the PHMQ is targeted towards (i.e., ages 3-5 years). Therefore, the activities are developmentally appropriate (see Supplementary Materials, Appendix 2, Table 1 for a detailed breakdown of the items, how each item was generated and initial item reduction criteria).

\section{Study 2: An Overview}

Questionnaire refinement (Table 1: Study 2) involved parents with children aged 3 to 5 years old taking part in the PHMQ. The aim of Study 2 was to examine how well items confirmed expectations concerning the psychometric properties of the new measure (Hinkin, 1998), including examining whether items produce necessary variance for subsequent statistical analyses (Stone, 1978). Study 2 addressed construct validity, which incorporated two psychometric properties, factor structure and scale score reliability. Furthermore, it is important that the response scale used (e.g., rank order or rating items) for the items produces necessary variance for subsequent statistical analyses (Stone, 1978).

\section{Method}

\section{Participants}

A total of 172 parents/guardians took part in the PHMQ. To acquire an equal spread of participants across SES through data collection, the proportion of free school meals (FSM) per school was calculated across Northern Ireland, using Department of Education (2014) statistics. It should be noted that FSM is an imperfect proxy of mothers and partners' education and social class (Hobbs \& Vignoles, 2007). Therefore, to avoid imperfect proxy bias (i.e., a proxy that correlates with the key variable but cannot be understood in isolation) parents were asked in the PHMQ to complete eight questions from the National Statistics Socio-economic Classification (NS-SEC; Rose \& Pevalin, 2010), which allowed the researcher to derive SES using the Standard Occupational Classification (SOC). The FSM statistics were divided into three proportions to distinguish schools that had low (4-18\%), medium (19-58\%) and high (59-85\%) FSM eligibility. The average FSM eligibility was $37.7 \%$. It was anticipated that an equal spread of pre-schools would be contacted from the three FSM eligibility categories. However, there was a low participation rate from the pre-schools in 
the medium FSM eligibility category, so more pre-schools were contacted from this category. Participants were recruited through 11 local pre-schools and two privately owned soft-play centres. A soft-play centre is a soft obstacle play area for children up to the age of 8 years-old at which parents/guardians supervise play. Thus, it was deemed an ideal area to target parents with children aged between 3 and 5 years old. The proportion of PHMQ returned from each of the low, medium and high FSM categories were $30,42.5$ and $27.5 \%$, respectively.

The sample consisted of 148 mothers, 18 fathers, three grandparents, two foster parents and one adoptive parent. The target child that parents/guardians were responding to questions about were aged between 36 and 60 months $\left(M_{\text {age }}=\right.$ 46.2 months; $52.3 \%$ female), with $85.5 \%$ of the target pre-school child having sibling/s $(N=147)$. The parents/guardians were between 23 and 65 years old $\left(M_{\mathrm{age}}=35.26\right.$ years). SES data was converted into a three-class categorical variable as described in NS-SEC (Rose \& Pevalin, 2010), this can be assumed to involve a form of hierarchy: high SES (50.7\%), middle SES (17.5\%), and low SES (25.5\%).

\section{Procedure}

The questionnaire was piloted $(N=10)$ to assess completion time and the ensure that the presentation was easy to read and understand. The questionnaire took approximately 10-15 minutes to complete and adjustments were made to the questionnaire to make sure participants would understand the terminology. After these changes were made the PHMQ was tested. No pilot data, at any point in this study, was used in analysis (e.g., for the exploratory factor analysis [EFA]). The participants that completed the PHMQ in the play centres did the questionnaire on the day they agreed to the study and they did not take them home. The participants who completed the PHMQ in the pre-schools returned the PHMQ to the child's teacher for collection in sealed envelopes to maintain confidentiality.

\section{Data Analysis}

Data was entered by two researchers and was verified to ensure $100 \%$ validity. A subject-to-variable ratio of 1:4.5 was achieved with 172 participants and 38 variables included in the EFA. This is consistent with previous research which suggests that a ratio of 1:3-1:6 subject-to-variable is acceptable (Arrindell \& Van der Ende, 1985; Cattell, 1978).

\section{Results}

\section{Questionnaire Refinement}

The PHMQ consisted of eight dimensions: 1) parent expectation of their children's academic success, 2) child maths literacy, 3) child counting ability, 4) parent-child teaching methods (e.g., what are the specific things parents say or do to encourage and support their child to learn maths?), 5) target child-sibling interactions (e.g., what numerical activities siblings are most likely to do together?), 6) parent's view of their child's understanding of numeracy, 7) caregivers support of numeracy learning in the home and 8) frequency of maths activities scale. See Supplementary Materials, Appendix 2, Table 1 for a detailed breakdown of the items, how each item was generated and initial item reduction criteria.

The first three dimensions, mentioned above, are known as benchmark questions as they give context to results by allowing comparison between participant responses. These are essential questions that gauge the background of the parents expectations for their child and the child's ability level. Each of these three dimensions had good variance and were retained for the final PHMQ. The next two dimensions parent-child teaching methods and target child-sibling interactions were named as interaction questions as they involve the target child interacting with both parents and siblings. The section parent-child teaching methods was kept due to good variation in results. However, the target child-sibling interactions (originally 13 questions) were reduced due to lack of variability, potentially explained by "halo effect" (i.e., parents wanting their child to be perceived favourably by reporting that they take part in an activity that may be too advanced for them). This finding was also discovered in the previous qualitative interviews (Cahoon et al., 2017). Therefore, 11 ranking options for target child-sibling interactions were reduced to seven ranking options. The threshold for cut off was any rank option that scored over $20 \%$ in the least likely categories. The reason for reducing rank order options was that participants found it too difficult to rank order 11 options. However, after reduction to seven ranking options this question piloted $(N=10)$ again and was still found to be difficult to complete. Therefore, this question was changed to match the 5-point Likert scale of the frequency of maths activities scale. The parent's view 
of their child's understanding of numeracy and caregivers support of numeracy learning in the home were removed due to lack of variability in results. There was a lack of variance in these questions indicating that they were classic "halo effect" questions (Fitzpatrick, 1991; Wilson, Hewitt, Matthews, Richards, \& Shepperd, 2006).

The frequency of maths activities scale of 38 questions, were analysed using EFA to investigate variable relations for this complex concept. These items were analysed using a principle components analysis with oblique rotation (direct oblimin). Table 2 summarises the factor loadings after rotation for the frequency of maths activities scale. The Kaiser-Meyer-Olkin measure verified the sampling adequacy for the analysis $(\mathrm{KMO}=0.80)$, and all KMO values for individual items were greater than 0.59. Five factors, comprising 28 items, had eigenvalues over Kaiser's criterion of 1 and in combination explained $53.14 \%$ of the common variance. The factors were labelled as follows; 1 ) parent-child interactions, 2) computer maths games, 3) TV programmes, 4) shape and 5) counting. Ten items did not load onto any factor and therefore these were removed from further analysis and questionnaire administration. To note, there is an item that factored into the parent-child interactions subscale that involves shape (i.e., Asking shape related questions [e.g., "how many sides does a circle have?"]). However, theoretically this makes sense as this activity would involve a parent interacting with their child to ask shape related questions. Cronbach's alpha for the full scale was .89. Cronbach's alpha for the subscales were acceptable, ranging from .76 for the counting factor to .81 for both the parent-child interactions and computer maths games factors, thus display good internal reliability.

Table 2

Summary of Exploratory Factor Analysis Results for Frequency of Maths Activities Scale

\begin{tabular}{|c|c|c|c|c|c|}
\hline \multirow[b]{2}{*}{ Items } & \multicolumn{5}{|c|}{ Rotated Factor Loadings } \\
\hline & $\begin{array}{l}\text { Parent-Child } \\
\text { Interactions }\end{array}$ & $\begin{array}{l}\text { Computer Maths } \\
\text { Games }\end{array}$ & TV Programmes & Shape & Counting \\
\hline Identifying names of written numbers & .65 & -.01 & .11 & .08 & .03 \\
\hline Write numbers & .59 & .05 & .06 & .03 & .14 \\
\hline $\begin{array}{l}\text { Teaching about measurements (e.g., baking } \\
\text { or height) }\end{array}$ & .54 & -.04 & -.03 & .02 & -.18 \\
\hline $\begin{array}{l}\text { Time terminology (e.g., big hand, little } \\
\text { hand) }\end{array}$ & .50 & .09 & -.05 & -.03 & -.07 \\
\hline $\begin{array}{l}\text { Asking shape related questions (e.g., "how } \\
\text { many sides does a circle have?") }\end{array}$ & .49 & .07 & -.09 & .20 & -.12 \\
\hline $\begin{array}{l}\text { Scenarios number games (e.g., "if I have } \\
\text { two toy cars and I take one away, how } \\
\text { many cars do I have?") }\end{array}$ & .49 & .10 & .04 & -.09 & -.25 \\
\hline $\begin{array}{l}\text { Teaching about money (e.g., playing shop } \\
\text { or buying sweeties) }\end{array}$ & .43 & .12 & -.10 & .02 & -.28 \\
\hline Sticker books & .38 & -.02 & .18 & .14 & -.08 \\
\hline $\begin{array}{l}\text { Maths related websites (e.g., } \\
\text { coolmaths.com) }\end{array}$ & -.02 & .71 & .00 & -.05 & .01 \\
\hline $\begin{array}{l}\text { Racing games (e.g., the faster they complete } \\
\text { sums, the faster the boat moves) }\end{array}$ & -.17 & .67 & .03 & .01 & -.02 \\
\hline
\end{tabular}


Rotated Factor Loadings

\begin{tabular}{|c|c|c|c|c|c|}
\hline Items & $\begin{array}{l}\text { Parent-Child } \\
\text { Interactions }\end{array}$ & $\begin{array}{l}\text { Computer Maths } \\
\text { Games }\end{array}$ & TV Programmes & Shape & Counting \\
\hline $\begin{array}{l}\text { Size/matching apps (e.g., "put the big skirt } \\
\text { on the small girl") }\end{array}$ & -.03 & .65 & .04 & .07 & -.01 \\
\hline Maths applications (e.g., Number Jacks) & .19 & .63 & .10 & -.05 & -.01 \\
\hline Add and subtraction games & .20 & .60 & .09 & -.04 & .01 \\
\hline $\begin{array}{l}\text { Filling in the gap number games (e.g., what } \\
\text { is next in the sequence?) }\end{array}$ & .16 & .51 & -.06 & .07 & -.01 \\
\hline Watching number related TV shows & .13 & .00 & .89 & -.07 & -.03 \\
\hline $\begin{array}{l}\text { Rhyming TV shows involving numbers } \\
\text { (e.g., Number Jacks) }\end{array}$ & .03 & .11 & .85 & .02 & -.04 \\
\hline $\begin{array}{l}\text { Watch educational programs (e.g., Dora the } \\
\text { Explorer) }\end{array}$ & -.15 & .13 & .38 & .14 & -.19 \\
\hline Sorting shapes & -.03 & .06 & -.03 & .62 & -.19 \\
\hline Sorting objects by size & -.05 & .04 & -.04 & .61 & -.34 \\
\hline $\begin{array}{l}\text { Creating patterns with objects (e.g., } \\
\text { arranging blocks into shapes) }\end{array}$ & .10 & .12 & -.12 & .61 & .02 \\
\hline Playing with building blocks & -.04 & -.04 & .12 & .58 & .15 \\
\hline Play with jigsaws & .09 & -.12 & .08 & .54 & .04 \\
\hline Pairing/matching games & .07 & .09 & -.03 & .44 & -.13 \\
\hline $\begin{array}{l}\text { Counting out food, dinner plates, knives } \\
\text { and forks }\end{array}$ & -.04 & .01 & .11 & .09 & -.61 \\
\hline Counting & .07 & -.09 & .05 & -.07 & -.59 \\
\hline $\begin{array}{l}\text { Counting objects (e.g., ducks in bath, } \\
\text { blocks, new toys, books) }\end{array}$ & .04 & .05 & .06 & .15 & -.55 \\
\hline Counting on fingers/hands & .15 & .01 & .02 & .01 & -.55 \\
\hline $\begin{array}{l}\text { Comparing sets of objects (e.g., brother has } \\
\text { more than mum) }\end{array}$ & .09 & .20 & -.03 & .05 & -.52 \\
\hline Eigenvalues & 7.16 & 2.39 & 2.14 & 1.67 & 1.53 \\
\hline$\%$ of variance & 25.58 & 8.52 & 7.63 & 5.95 & 5.45 \\
\hline $\mathrm{a}$ & .81 & .81 & .79 & .78 & .76 \\
\hline
\end{tabular}

Note. Factor loadings over .40 appear in bold. $N=172$.

Overall, from the initial 69 items, 19 items (14 deductive and five inductive generated items) were removed for different reasons mentioned previously. Thus, a total of 50 items were retained. Through the item reduction process, the PHMQ contained six home environment dimensions; 1) parent expectation of their children's academic success, 2) child maths 
literacy, 3) child counting ability, 4) parent-child teaching methods, 5) target child-sibling interactions and 6) frequency of maths activities scale. The dimensions called child's understanding of numeracy and support questions were removed.

\section{Study 3: An Overview}

After the development of the PHMQ, the scale validation process involved two studies, the first being qualitative to assess content and criterion validity (Table 1: Study 3). Content validity considers whether appropriate questions have been asked in the measure (Nunes et al., 2005). It allows for comparison of the themes identified in the questionnaire with those emerging in subsequent interviews (Nunes et al., 2005). Criterion validity investigates contrast cases of participants with very high or very low scores on each of the themes within a questionnaire and compares the contrasting cases to the interview responses (Nunes et al., 2005). This enhances the validity of the dimensions included within the PHMQ.

\section{Method}

\section{New Dimension}

At this stage before the following semi-structured interviews were conducted, a new dimension called the number game checklist was developed and added to the PHMQ. Skwarchuk et al. (2014) created a measure to assess the informal numeracy experiences by developing a number games title checklist. This framework was adapted from Sénéchal and LeFevre (2002) study that used parent's knowledge of storybook titles as a proxy measure of informal home literacy practices. The number games title checklist by Skwarchuk et al. (2014) was created for a Canadian sample, thus a new, culturally appropriate, number games checklist was developed as a measure of informal home numeracy practices (number games exposure checklist) so that the games were relevant to the United Kingdom (UK). The rationale for the inclusion of this dimension is so that the measure can assess informal home numeracy practices through parent's recognition of board games alongside the frequency of maths activities scale that potentially assesses both formal and informal home numeracy practices. Note that a two-factor model based on the original definitions of direct and indirect numeracy activities by LeFevre et al. (2009) was explored through a confirmatory factor analysis (CFA) in the Supplementary Materials (see Appendix 5 for details).

To develop the board game checklist information was gathered about commercially available board games suitable for children aged 3 to 6 years both in store and online from three retail establishments. To compile the list of games, selection criteria were used to allow parents a chance to have knowledge of the games. In Sénéchal, LeFevre, Hudson, and Lawson (1996) book title checklist fairy tale games (i.e., those games that involved fairy tale characters from movies or television) for which a movie or television version existed were eliminated due to possible over familiarisation. To allow for the games to be readily available to parents only those game titles that were available in two of the three retail establishments were selected. Lastly to ensure that the games were accessible to all parents regardless of income level only games that were under $£ 15$ were selected. Games were categorised according to whether they included numerical components (counting, adding and recognising numbers). In contrast to Skwarchuk et al. (2014) that included 25 titles (10 numerical games, 10 non-numerical games, and five plausible but non-existent games), this board game checklist consisted of 30 game titles; 10 numerical; 10 non-numerical and 10 plausible but non-existing games. The number of plausible but non-existent games was increased to 10 as this was equal to that of the numerical and non-numerical game.

The newly created number games checklist was cross-referenced with Skwarchuk et al. (2014) number game exposure checklist. Four numerical, two non-numerical and one plausible but non-existing games were taken from Skwarchuk et al. (2014) checklist as they also reached the selection criteria used in this study. As in previous home numeracy research (Skwarchuk et al., 2014), parents were asked to indicate their familiarity with children's game titles. Parents were asked not to guess or stop to verify any game titles online or in a catalogue. Participants were informed that non-existing games were included in the checklist to minimise guessing. To calculate the number game checklist score, the total of correctly marked number games was corrected for guessing (e.g., if seven number games and one non-existing games were selected, this was scored as $(7-1 / 10) \times 100=60 \%$; Skwarchuk et al., 2014). 
Therefore, overall the PHMQ was made up of seven-home environment relevant dimensions including the informal home numeracy practices (number game exposure) section to the PHMQ. The updated PHMQ with the seven-home environment relevant dimensions was subsequently piloted with parents/guardians to confirm refinement $(N=30)$.

\section{Participants}

Eight participants $\left(M_{\text {age }}=37.8\right.$ years) agreed to take part in the PHMQ and the interview; six mothers, one father and one grandparent. The target child ( $50 \%$ female) were aged between 36 and 49 months ( $M_{\text {age }}=42.8$ months). Data saturation was reached in the eight interviews which is consistent with other studies (Isman, Ekéus, \& Berggren, 2013; Isman, Mahmoud Warsame, Johansson, Fried, \& Berggren, 2013). Data saturation was achieved when further coding was not achievable, thus the ability to obtain additional new information from further interviews was no longer possible (Fusch \& Ness, 2015).

\section{Procedure}

The interviews took place at two soft-play centres that had been used as sites in Study 2. The topic guide of questions asked to the parents included questions such as, "Do you think your child is interested in maths? If so, why?" and "Can you compare the frequency and structure of mathematical activities to reading at home?" These questions were used as they were deemed appropriate to gain sufficient information for content and criterion validity as these were the same questions asked in the original interviews (Study 1; Cahoon et al., 2017). Half of the participants were administered the questionnaire before the interview and half of the parents were given the questionnaire after the interview. The individual interviews lasted approximately 40 minutes and the PHMQ took approximately 10 minutes to complete. The interviews were recorded and transcribed before analysing.

\section{Data Analysis}

The subscales in the frequency of maths activities scale were used to assess content and criterion validity. The other dimensions from the PHMQ such as the frequency of reading compared to numeracy, target child-sibling interaction, structure of the HNE and parent-child teaching methods, will be evaluated to assess the content validity of the PHMQ. The parents' responses were coded using NVivo (Version 11) into content categories based on the five subscales within the frequency of maths activities scale. Criterion validity was assessed through contrasting cases that were identified by obtaining the total scores for the five subscales and were calculated for each participant. Scores ranged from 0 to 4 , based on a 5-point Likert scale. Respondents with low scores were more likely to answer that an activity did not occur and hence would have a score closer to 0 . Respondents with high scores would be more likely to answer that an activity occurred almost daily and thus score closer to 4 . The parents' interview transcripts were then searched for comments relevant to the subscales.

\section{Results}

\section{Content Validity}

There was an agreement between parents' views in the interview and those assessed by the PHMQ. Issues surrounding the six dimensions of the PHMQ (i.e., 1) parent expectation of their children's academic success, 2) child maths literacy, 3) child counting ability, 4) parent-child teaching methods, 5) target child-sibling interactions and 6) frequency of maths activities scale) and the five frequency of maths activities subscales were mentioned in the eight interviews and used to assess the content validity. The definitions and sample comments illustrating each dimension and factor are summarised in the Supplementary Materials (see Appendix 3, Table 2). Appendix 3, Table 2 shows that each factor was mentioned from the frequency of maths activities scale in the interview thus, all items were retained in the scale.

Emerging Topic - An emerging topic was identified in the interviews, which suggested the need for increasing the breadth of the frequency of maths activities scale. YouTube was mentioned by half the participants. Children watched a range of videos including educational videos. Some examples of the types of videos children watched are reported below; 
"She likes watching a couple of YouTube videos. She loves the videos where people open, they are called blind bags, the likes of My Little Pony or Paw Patrol. It's almost like a kinder eggs surprise thing and it will have one of the characters in them. She counts the characters sometimes"-Participant 3

"Oh Number Jacks. He has only started to watch Number Jacks on YouTube. He likes that. It's quite good"-Participant 4

"They usually watch YouTube videos. People have made up YouTube videos using the characters from Frozen or Paw Patrol or whatever and changing their colours or do the finger family"-Participant 6

Summary of Content Validity - Two new additional topics arose from the current interviews that were not mentioned in the previous interviews. The first was that parent's interest in mathematics may influence the frequency of maths activities occurring in the home, therefore a question related to this topic was added to the PHMQ. The second was that parents reported watching videos with mathematics content on YouTube with their children, therefore the item "Maths related YouTube videos" was added to the frequency of maths activities scale. Overall, the analysis of interviews confirmed the dimensions included in the PHMQ.

\section{Criterion Validity}

It is only possible to use criterion validity on the frequency of maths activities scale within the PHMQ as criterion validity involves contrasting cases of high and low scores, possible through a Likert scale. Analysing contrasting cases indicates that in the frequency of maths activities subscales there are differences between the extreme high and low scores. The high and low contrasting cases with sample comments illustrating each subscale dimension are summarised in the Supplementary Materials (see Appendix 4, Table 3). Some noteworthy findings were that time limits were important with regards to the frequency of computer usage; this is one reason for the varying frequencies of computer maths games subscale. The types of TV programmes being watched may influence the frequency and perhaps be one reason for the contrasting cases. This would be expected as the TV programmes subscale only involves questions about educational programmes. Therefore, those children who are mostly watching non-educational TV programmes would score low on the TV programmes subscale. It is important to note that a child's interest plays a factor in the TV programmes they want to watch (Cahoon et al., 2017) and this could influence high and low frequencies on this subscale. Nevertheless, the subscale seems to identify contrasting cases well. Parents who scored the lowest on the counting subscale stated that counting was mostly brought up by the parent. Whereas parents who scored high on the counting stated that mathematics was brought up naturally by their child and hence counting may be covered more often in the home if both the parent and the child are likely to bring up counting. Overall, there are clear differences between the views of parents with contrasting frequency scores as assessed through the interviews.

\section{Study 4: An Overview}

As previously stated, the scale validation process involved two studies the second being quantitative; construct validity (i.e., CFA; Table 1: Study 4).

\section{Method}

\section{Participants}

152 parents with children aged 43 to 54 months ( $M_{\text {age }}=48$ months) agreed to complete the PHMQ. 136 (89\%) participants (91\% female) returned the PHMQ and were 34.9 years-old ( $S D=5.7$, Range 21-46 years). The same FSM classification approach was used as Study 2. The proportion of PHMQ returned from each of the FSM Eligibility categories were 32, 50 and 18\%, respectively. There were $39.5 \%$ parents from high SES, $19.7 \%$ from middle SES and $23.7 \%$ from low SES 
backgrounds. The additional $17.1 \%$ represents missing data or that the responding parent had never worked, had been long-term unemployed or was a full-time student.

\section{Procedure}

The parent of the target child was asked to complete the PHMQ. Parents who complete and return the PHMQ were entered into a prize draw for a $£ 50.00$ Amazon voucher. The PHMQ was returned to the pre-school teacher and collected by the researcher.

\section{Data Analysis}

A CFA was all completed in Mplus Version 1.5 (Muthén \& Muthén, 1998, 2017). Mplus was used to examine the factor structure instead of SPSS as Mplus allows for the researcher to place each item in the factor suggested by the exploratory factor analysis to test if the model fits. A CFA was utilised on the five subscales found in Study 2.

\section{Results}

\section{Construct Validity}

A CFA with robust maximum likelihood was conducted in Mplus. This approach has been widely used in CFA models when continuous observed variables slightly or moderately deviate from the normality and it is superior to maximum likelihood (Li, 2016). In Figure 1 the five-factor model is presented.

The selection of the most appropriate model was based upon goodness of fit statistics (Table 3). For more information on other models that were examined (i.e., One factor, total frequency of maths activities, five-factor second order models and two-factor model based on the original definitions of direct and indirect numeracy activities by LeFevre et al. [2009]) refer to the Supplementary Materials (see Appendix 5). The model had acceptable model fit indices reporting a Comparative Fit Index (CFI) of .83 and a Tucker Lewis Index (TLI) of .81. Good fitting models are indicated by a CFI of $>.95$ (better model: $>.97$ ) and the same cut-off value for TLI applies (Geiser, 2012). A CFI $>.90$ is often regarded as an indicator of an adequate model fit (Awang, 2012; Coroiu et al., 2018; Hair, Black, Babin, \& Anderson, 2010) the same cut-off value for TLI applies (Awang, 2012; Coroiu et al., 2018; Forza \& Filippini, 1998).

The CFI and the TLI are incremental fit indices that compare the fit of the target model to the fit of a baseline model (Geiser, 2012). In Mplus the baseline model, also known as the null independence model, assumes that the population covariance matrix of the observed variables is a diagonal matrix, in other words, it is assumed that there is no relation between any of the variables (Geiser, 2012). As a consequence, it is possible that the null model is "too good," meaning that the average level of correlations in the current data is rather low. In this case, Kenny (2015) argued that CFI should not be computed if the RMSEA (i.e., Root-Mean-Square Error of Approximation) of the null model is less than .158 as the CFI obtained will be too small a value (Beldhuis, 2012; Kenny \& McCoach, 2003). When investigating the RMSEA values the model demonstrated acceptable RMSEA values (< .08) (Awang, 2012), the RMSEA value was .07. Therefore, the five-factor model is a reasonable model.

The SRMR (i.e., Standardised Root Mean Square Residual) coefficient is a standardised measure for the evaluation of the model residuals, however SRMR is somewhat biased by sample size. Marsh, Hau, and Wen (2004) state that the SRMR values for solutions based on small sample sizes are unacceptable (greater than .08), whereas those based on large sample sizes are acceptable. A value < .08 is generally considered a good fit (Hu \& Bentler, 1999). Therefore, taking into consideration all fit criteria for assessing goodness of fit the model presents acceptable fit indices (CFI $=.83$, TLI $=.81$, RMSEA $=.07$, SRMR $=.072$ ), thus it seems reasonable that a five-factor model be deemed a suitable measurement model. 


\section{Figure 1}

Five-Factor Model of the Frequency of Maths Activities Scale in the PHMQ

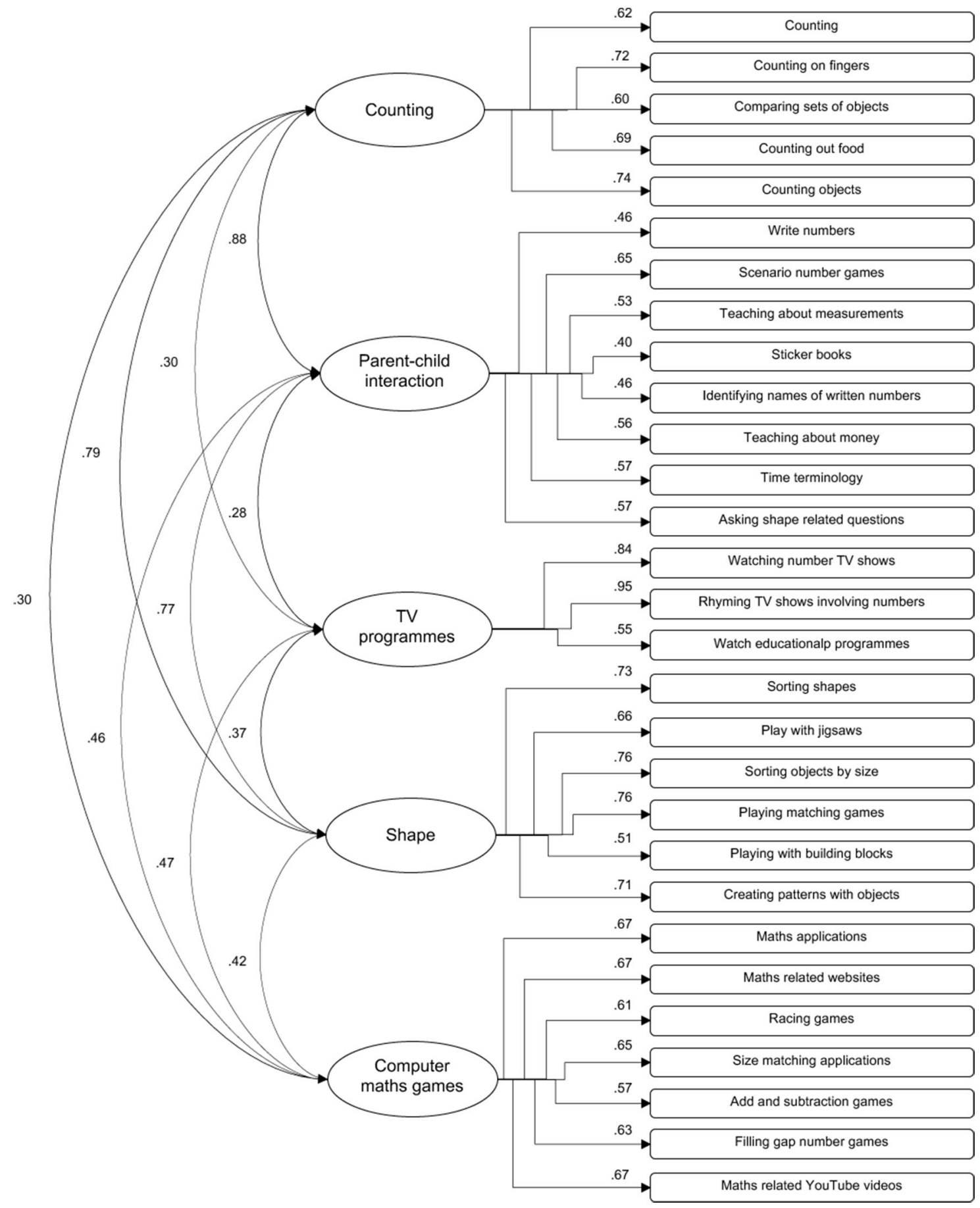


Table 3

Model Fit Statistics for the Alternative Models of Frequency of Maths Activities

\begin{tabular}{|c|c|c|c|c|c|c|c|c|c|c|}
\hline $\begin{array}{l}\text { Model } \\
\text { no. }\end{array}$ & Model Explained & $\chi^{2}(p)$ & $d f$ & CFI & TLI & $\begin{array}{c}\text { RMSEA }[90 \% \mathrm{CI}] \\
p\end{array}$ & SRMR & AIC & BIC & $\begin{array}{l}\text { Sample-size } \\
\text { adjusted BIC }\end{array}$ \\
\hline 1 & One factor model & $\begin{array}{l}992.714 \\
(<.001)\end{array}$ & 377 & .57 & .53 & $\begin{array}{c}.110[.101, .118] \\
<.001\end{array}$ & .109 & 11841.537 & 12094.938 & 11819.717 \\
\hline 2 & Five-factor model & $\begin{array}{l}633.871 \\
(<.001)\end{array}$ & 367 & .81 & .79 & $\begin{array}{c}.073[.063, .083] \\
<.001\end{array}$ & .078 & 11480.253 & 11762.780 & 11455.925 \\
\hline 3 & $\begin{array}{l}\text { Five-factor second order } \\
\text { model }\end{array}$ & $\begin{array}{l}644.616 \\
(<.001)\end{array}$ & 371 & .81 & .79 & $\begin{array}{c}.074[.064, .083] \\
<.001\end{array}$ & .081 & 11482.686 & 11753.563 & 11459.361 \\
\hline 4 & $\begin{array}{l}\text { Two-factor model (original } \\
\text { direct and indirect } \\
\text { activities) }\end{array}$ & $\begin{array}{l}992.703 \\
(<.001)\end{array}$ & 376 & .57 & .53 & $\begin{array}{c}.110[.102, .118] \\
<.001\end{array}$ & .109 & 11842.808 & 12099.121 & 11820.737 \\
\hline
\end{tabular}

Note. Estimator = MLR; $n=136 ; \chi^{2}=$ Chi-square Goodness of Fit statistic; $d f=$ degrees of freedom; $p=$ Statistical significance; CFI = Comparative Fit Index; TLI = Tucker Lewis Index; RMSEA $(90 \%$ CI $)=$ Root-Mean-Square Error of Approximation with $90 \%$ confidence intervals; BIC = Bayesian Information Criterion; AIC = Akaike information criterion.

\section{The Additional "Maths Related YouTube Videos" Item}

As discussed in Study 3, an additional item was discovered through the process assessing content validity and added into the frequency of maths activities scale. This item was named "Maths related YouTube videos." As confirmed by the interviews with parents during content analysis, younger children mostly use YouTube to consume traditional, "TV-like" content (OfCom, 2016). Therefore, the item "Maths related YouTube videos" was initially added to the TV programmes subscale of the frequency of maths activities scale.

However, on examination of the modification indices (i.e., restrictions that may be relaxed to obtain a significant improvement of the global model fit; Geiser, 2012) it was apparent that the item, "Maths related YouTube videos," should be placed within the computer maths games subscale which made for better model fit indices. The fit indices for the new item placed in the TV programmes subscale were CFI $=.81$, TLI $=.79$, RMSEA $=.073$, SRMR $=.078$. Whereas, the fit indices for new item placed in the computer maths games subscale were CFI $=.82$, TLI $=.81$, RMSEA $=.070$, SRMR $=.072$. As suggested by the modification indices and the model fit statistics the new item was placed in the computer maths games subscale. This was the only suggested modification indices, further evidence that the five-factor model is a suitable measurement model.

\section{Discussion}

By following the procedures used by Hinkin (1998) and Nunes et al. (2005) the new PHMQ measure demonstrates construct, content, criterion validity and satisfies APA standards for psychometric adequacy (APA, 1995; Hinkin, 1998), which was the ultimate objective of this scale development and validation process. The scale development process (Table 1: Study 1 and 2), presented construct validity, which addressed two psychometric properties. Firstly, the five-factor structure of the frequency of maths activities scale found through the EFA demonstrated that the factor structure and scale score reliability had high levels of reliability ( $\alpha=.76$ to .81$)$.

This high level of reliability is consistent with other studies in which a factor analysis was used to refine the HNE measure. For instance, LeFevre et al. (2009) reported a reliability between .71 and .84 for their numeracy-related activities measure comprising of four factors; 1) number skills, 2) games, 3) applications and 4) number books. Kleemans et al. (2012) established two factors in their home numeracy questionnaire, 1) parent-child numeracy activities and 2) parents' numeracy expectations, with a reliability of .76 and .83, respectively. Further, Lukie et al. (2014) established a four-factor model, 1) exploratory cognitive play, 2) active play, 3) crafts, and 4) screen time, within their child-interest scale with a reliability ranging between .60 to .79 . LeFevre et al. (2009) used factor analysis to classify activities reported 
in the 1) number skills and 4) number books subscales as direct teaching activities and the 2) games and 3) application factors as indirect experiences. However, the results of the factor analysis in the current study does not replicate LeFevre et al. (2009) findings of direct versus indirect experiences, instead five separate subscales were identified, 1) parent-child interactions, 2) computer maths games, 3) TV programmes, 4) shape and 5) counting.

Each of the studies mentioned above contribute to the growing body of research on the influence of the home environment on mathematical development. However, the unique aspect of the current PHMQ measure is its rigorous development through use of both deductive and inductive approaches. Skwarchuk (2009) drew numerical content from a questionnaire, diary entries and videotaped play sessions in a Canadian setting. Similar to Skwarchuk (2009) the aim was to draw out mathematical content that occurred in the home through interviews within a UK content. Literature demonstrates equivocal definitions (Cahoon et al., 2017); rendering is difficult to determine what defines an effective HNE that facilitates development in mathematics. This is further complicated by the lack of agreement on what parental involvement and interactions matter most. The current study broadens the definition of the HME through interviews with parents, allowing items to be generated inductively and therefore developing a comprehensive measure of the HME for preschool children following well-established procedures such as Hinkin (1998) and Nunes et al. (2005). This rigorous approach ensures that the measure captures the actual HNE that young children experience.

The scale validation process (Table 1: Study 3 and 4) consisted of content and criterion validity. Content validity demonstrates that the themes included in the PHMQ are raised by parents in the interviews. The examination of criterion validity showed that there were clear differences between the views and experiences of parents with low and high scores across all five PHMQ subscales. One of the new items that was spontaneously raised by the parents was that their children watched a range of videos on YouTube, including educational videos. YouTube is predominantly utilised, with $37 \%$ of 3 to 4 -year-olds and 54\% of 5 to 7 -year-olds, using the YouTube app or website (OfCom, 2016). As confirmed by the interviews with parents, younger children mostly use YouTube to consume traditional, "TV-like" content (OfCom, 2016). Therefore, the item "Maths related YouTube videos" was placed within the computer maths games subscale within the frequency of maths activities scale based on the model fit indices from the CFA. A CFA was used to quantitatively assess the quality of the five-factor structure of the frequency of maths activities scale offering evidence of the construct validity of the scale (Hinkin, 1998). Taking into consideration all criteria for assessing goodness of fit the five-factor model it was deemed a suitable measurement model, confirming the findings from the EFA (Study 2).

Overall, there are more numeracy-based items than mathematics-based items within the PHMQ. This is reflective of the target age group (ages 3-5 years) for the Pre-school Home Mathematics Questionnaire. Therefore, the activities included in the questionnaire are developmentally appropriate. The questionnaire is titled the Preschool Home Mathematics Questionnaire due to broader items than simply numeracy being included, such as shape and patterns. Similar to Clements, Sarama, and Liu (2008), who created a measure to access the mathematical knowledge and skills of children aged 3 to 7 years, the PHMQ broadly covers mathematics and would be proportional for the amount of non-numeracy maths presented in preschool.

\section{Contribution to Research}

As far as the authors are aware, this was the first study that uses both an inductive and deductive approach to develop an HME questionnaire, which increases the chance of content validity in the final scale (Hinkin, 1998). Previous scales (i.e., frequency of number activities scales) have rarely gone beyond creating items using a deductive approach. Further, these scales have rarely been validated beyond construct validity (e.g., LeFevre et al., 2009). Schoenfeldt (1984, p. 78) stated that "the construction of the measuring devices is perhaps the most important segment of any study." Therefore, the PHMQ, in particular the frequency of maths activities scale, was evaluated across five psychometric properties (i.e., construct validity, factor structure, scale score reliability, content validity and criterion validity) and therefore satisfies APA standards for psychometric adequacy (APA, 1995; Hinkin, 1998). As with all questionnaire methods the PHMQ, is a self-report measure of the HNE and could be subject to social desirability bias. However, the PHMQ has been rigorously developed to allow researchers to obtain data efficiently to further understand how parents contribute to their preschool child's learning. Therefore, the PHMQ is a good measure to use with parents who have children between the ages of 3 and 5 as it is both developmentally appropriate and rigorously developed. 
At this stage of the PHMQ development and validation, only one form of criterion validity has been included and no assessment of predictive validity has been reported. Due to the mixed findings in this area of research (Thompson et al., 2017) it is difficult to hypothesise what we would anticipate in terms of predictive validity. Thompson et al. (2017) examined studies relating HNE practices to mathematics performance and established that there are mixed findings in the literature. Some studies show positive directionality (i.e., Anders et al., 2012; Niklas, Cohrssen, \& Tayler, 2016), no significant relations (i.e., Blevins-Knabe et al., 2000; Missall et al., 2015) or indicate negative relations (i.e., Blevins-Knabe \& Musun-Miller, 1996) between HNE practices and mathematics performance. In fact, both positive and null relationships (i.e., DeFlorio \& Beliakoff, 2015; Zippert \& Ramani, 2016) or both positive and negative relations (i.e., Skwarchuk, 2009) have been observed within the same study. Therefore, rather than focusing on the predictive nature of the PMHQ we aimed to generate a robustly developed measure with good construct validity, factor structure, scale score reliability, content validity and criterion validity. Thus, future research can utilse this measure to further assess if a relationship between the HME and mathematical development truly exists. Moreover, Daucourt's (2019) meta-analysis on the relationship between the HME and mathematics performance found, on average, a very small effect $(r=.14)$. One of the major limitations of previous studies is that the measurement development process in these studies either 1) reference LeFevre et al. (2009) scale without further attention to age, cultural, or setting specific concerns or 2) present final items and only discuss internal consistency (e.g., Kleemans et al., 2012). In measurement development, reporting a clear and transparent outline of the process that was undertaken to generate the final measure is essential (Hinkin, 1998). One of the core contributions of the current study is that we focus on the measurement development process and provide a model that can be used in other contexts across the numerical cognition field.

One of the issues that may be driving the inconsistency of findings in this area, is the lack of agreement on how the HME should be defined. Our study has addressed this issue by defining the HME from the perspective of the parent through the first study of the four presented in this paper (also see the initial qualitative research to this project, Cahoon et al., 2017). Therefore, the main aim of this paper was to rigorously develop and validate a measure of the home environment that went right back to redefining the HME and subsequently demonstrating high levels of content and criterion validity.

Further, this study goes beyond only including frequency of maths activities question by including questions on children's maths literacy and counting ability. Additional dimensions/items were discovered and included such as parent-child teaching methods (e.g., what are the specific things parents say or do to encourage and support their child to learn maths?) and target child-sibling interactions (e.g., what numerical activities siblings are most likely to do together?). In addition to children interacting with their parents/caregivers at home, interactions with others, such as siblings, have been observed to play an important role in learning numerical concepts (Howe et al., 2015; Howe, Ross, \& Recchia, 2011) however, these types of questions have rarely made it into HME questionnaires. These types of interaction questions could allow researchers to investigate if parent-child teaching methods and target child-sibling interactions help in the development of mathematical knowledge.

\section{Limitations}

Future research should attempt to align questionnaire measurement with other data collection techniques. This is particularly pertinent as the main focus of questionnaire based HNE measurement is the frequency of activities. Future studies should also attempt to measure the quality of the content of these activities and interactions which is a very difficult aspect to capture using questionnaires.

In both Studies 2 and 4 there are more participants in the high SES category, with the middle SES category having the least participants. Hence, although considerable efforts were made to acquire an equal spread of participants across SES. There were less parents in the middle SES category and then the low SES category than the high SES category. However, this could be expected as research has shown that lower SES parents were less likely than others to engage in their child's schooling (e.g., Braun, Noden, Hind, McNally, \& West, 2005; Moon \& Ivins, 2004; West, 2007).

Eight participant interviews were used in the criterion validity and although there were clear differences between the views and experiences of parents with low and high scores across all five PHMQ subscales the limited sample size used should be taken with caution. Further, it should be noted that the majority of items/questions used within the 
PHMQ are numeracy related which would be developmentally appropriate for the intended age group. However, the questionnaire involves home environment relevant dimensions beyond numeracy therefore it has been called the PHMQ so as not to be misleading.

\section{Future Recommendations}

Most HME questionnaires have been developed and used in home environments that reflect the developed world, for example Canada, America and the current PHMQ developed for a UK context. This is the first study within the UK that has created an HME questionnaire that is culturally specific, were items are not just deductive and drawn from other HME questionnaires such as Melhuish et al. (2008). Hence, this HME questionnaire alongside other available HME questionnaires may be context specific. There is a need for the development of an international measure that is developed and validated as rigorously as the current measure, but for the context of low-income country contexts. This study offered the theoretical and empirical framework of how an HME measure that reflects the home environment in low income countries could be created and validated to meet APA standards for psychometric adequacy (APA, 1995).

\section{Conclusion}

Some of the HME questionnaires have not provided adequate information about item generation and refinement, scale dimensionality, scale score reliability, or validity (e.g., Kleemans et al., 2012; LeFevre et al., 2009; Melhuish et al., 2008). In previous literature a major weakness to studying the HNE is the lack of information describing the psychometric integrity of scales used to measure the construct of the HNE. However, these studies have made a widespread impact on home learning environment research and the number of studies in this area have increased in recent years. The current study extends the rigour of HME questionnaire development and validation. This study provides details on psychometric integrity and appears to be psychometrically sound (Hinkin \& Schriesheim, 1989; MacKenzie, Podsakoff, \& Fetter, 1991). The PHMQ covers a vast array of HNE areas thus, it is concluded that the PHMQ can be used to successfully describe the HNE that a parent creates for their child to learn numeracy. Every learning experience in the home are shared learning experiences for children, whether this is between parents or siblings. The PHMQ can allow researchers to quickly obtain data to understand how parents contribute to their child learning numeracy related concepts and skills.

Funding: The authors have no funding to report.

Acknowledgments: The authors have no support to report.

Competing Interests: The authors have declared that no competing interests exist.

\section{Supplementary Materials}

This is the supplementary information for the paper named "Developing a Rigorous Measure of the Pre-School Home Mathematics Environment”. There are five appendices as follows (for access see Index of Supplementary Materials below):

1. The full original version of the Pre-school Home Mathematics Questionnaire (PHMQ) which was developed during Study 1 before questionnaire refinement and scale validation

2. Summary of items from PHMQ, how questions were generated and initial item reduction criteria

3. Content validity and

4. Criterion validity dimensions or subscales from PHMQ and sample commentary from interviews

5. Confirmatory factor analysis for the frequency of maths activities scale including one factor model (total frequency of maths activities), five-factor second order model, two-factor model based on the original definitions of direct and indirect numeracy activities by LeFevre et al. (2009) and the best fit model is also discussed 


\section{Index of Supplementary Materials}

Cahoon, A., Cassidy, T., Purpura, D., \& Simms, V. (2021). Supplementary materials to "Developing a rigorous measure of the pre-school home mathematics environment" [Appendices]. PsychOpen GOLD. https://doi.org/10.23668/psycharchives.4980

\section{References}

American Psychological Association (APA). (1995). Standards for educational and psychological testing. Washington, DC, USA: Author. Anders, Y., Rossbach, H. G., Weinert, S., Ebert, S., Kuger, S., Lehrl, S., \& von Maurice, J. (2012). Home and pre-school learning environments and their relations to the development of early numeracy skills. Early Childhood Research Quarterly, 27(2), 231-244. https://doi.org/10.1016/j.ecresq.2011.08.003

Anderson, A. G. (1998). Parents as partners: Supporting children's mathematics learning prior to school. Teaching Children Mathematics, 4(6), Article 331. https://doi.org/10.5951/TCM.4.6.0331

Arrindell, W. A., \& Van der Ende, J. (1985). An empirical test of the utility of the observations-to-variables ratio in factor and components analysis. Applied Psychological Measurement, 9(2), 165-178. https://doi.org/10.1177/014662168500900205

Awang, Z. (2012). Structural equation modeling using AMOS graphic. Shah Alam, Malaysia: Penerbit Universiti Teknologi MARA.

Beldhuis, H. (2012). The Proceedings of the 11th European Conference on e-Learning. Groningen, The Netherlands: University of Groningen.

Bjorklund, D. F., Hubertz, M. J., \& Reubens, A. C. (2004). Young children's arithmetic strategies in social context: How parents contribute to children's strategy development while playing games. International fournal of Behavioral Development, 28(4), 347-357. https://doi.org/10.1080/01650250444000027

Blevins-Knabe, B. (2016). Early mathematical development: How the home environment matters. In B. Blevins-Knabe \& A. M. B. Austin (Eds.), Early childhood mathematics skill development in the home environment (pp. 7-28). Cham, Switzerland: Springer.

Blevins-Knabe, B., Austin, A. B., Musun, L., Eddy, A., \& Jones, R. M. (2000). Family home care providers' and parents' beliefs and practices concerning mathematics with young children. Early Child Development and Care, 165(1), 41-58. https://doi.org/10.1080/0300443001650104

Blevins-Knabe, B., \& Musun-Miller, L. (1996). Number use at home by children and their parents and its relationship to early mathematical performance. Early Development and Parenting: An International fournal of Research and Practice, 5(1), $35-45$. https://doi.org/10.1002/(SICI)1099-0917(199603)5:1\%3C35::AID-EDP113\%3E3.0.CO;2-0

Braun, A., Noden, P., Hind, A., McNally, S., \& West, A. (2005). Final report of the evaluation of the Pupil Learning Credits pilot scheme (DfES Research Report RR687). Retrieved from www.dfes.gov.uk/research/data/uploadfiles/RR687.pdf

Burgess, S. R., Hecht, S. A., \& Lonigan, C. J. (2002). Relations of the home literacy environment (HLE) to the development of readingrelated abilities: A one-year longitudinal study. Reading Research Quarterly, 37(4), 408-426. https://doi.org/10.1598/RRQ.37.4.4

Cahoon, A., Cassidy, T., \& Simms, V. (2017). Parents' views and experiences of the informal and formal home numeracy environment. Learning, Culture and Social Interaction, 15, 69-79. https://doi.org/10.1016/j.lcsi.2017.08.002

Caldwell, B. M., \& Bradley, R. H. (1984). Home observation for measurement of the environment. Little Rock, AR, USA: University of Arkansas at Little Rock.

Cankaya, O., \& LeFevre, J. A. (2016). The home numeracy environment: What do cross-cultural comparisons tell us about how to scaffold young children's mathematical skills? In B. Blevins-Knabe \& A. M. B. Austin (Eds.), Early childhood mathematics skill development in the home environment (pp. 87-104). Cham, Switzerland: Springer.

Cattell, R. B. (1978). The scientific use of factor analysis. New York, NY, USA: Plenum.

Claessens, A., \& Engel, M. (2013). How important is where you start? Early mathematics knowledge and later school success. Teachers College Record, 115(6), 1-29.

Clements, D. H., \& Sarama, J. (2004). Learning trajectories in mathematics education. Mathematical Thinking and Learning, 6(2), 81-89. https://doi.org/10.1207/s15327833mt10602_1

Clements, D. H., Sarama, J. H., \& Liu, X. H. (2008). Development of a measure of early mathematics achievement using the Rasch model: The research-based early maths assessment. Educational Psychology, 28(4), 457-482.

https://doi.org/10.1080/01443410701777272 
Coroiu, A., Kwakkenbos, L., Moran, C., Thombs, B., Albani, C., Bourkas, S., \& Körner, A. (2018). Structural validation of the selfcompassion scale with a German general population sample. PLoS One, 13(2), Article e0190771. https://doi.org/10.1371/journal.pone.0190771

Daucourt, M. C. (2019). The home math environment and math achievement: A meta-analysis (Doctoral dissertation, Florida State University, FL, USA). ProQuest Dissertations Publishing.

Dearing, E., Casey, B. M., Ganley, C. M., Tillinger, M., Laski, E., \& Montecillo, C. (2012). Young girls' arithmetic and spatial skills: The distal and proximal roles of family socioeconomics and home learning experiences. Early Childhood Research Quarterly, 27(3), 458-470. https://doi.org/10.1016/j.ecresq.2012.01.002

DeFlorio, L., \& Beliakoff, A. (2015). Socioeconomic status and pre-schoolers' mathematical knowledge: The contribution of home activities and parent beliefs. Early Education and Development, 26, 319-341. https://doi.org/10.1080/10409289.2015.968239

Department of Education. (2014). School meals - 2013/14 statistical bulletin. Retrieved from http://www.deni.gov.uk/news/news-de-290414-school-meals-in.htm

Duncan, G. J., Dowsett, C. J., Claessens, A., Magnuson, K., Huston, A. C., Klebanov, P., . . Sexton, H. (2007). School readiness and later achievement. Developmental Psychology, 43(6), Article 1428. https://doi.org/10.1037/0012-1649.43.6.1428

Fitzpatrick, R. (1991). Surveys of patients satisfaction: I--Important general considerations. BMF: British Medical fournal, 302(6781), Article 887. https://doi.org/10.1136/bmj.302.6781.887

Forza, C., \& Filippini, R. (1998). TQM impact on quality conformance and customer satisfaction: A causal model. International fournal of Production Economics, 55(1), 1-20. https://doi.org/10.1016/S0925-5273(98)00007-3

Frijters, J. C., Barron, R. W., \& Brunello, M. (2000). Direct and mediated influences of home literacy and literacy interest on prereaders' oral vocabulary and early written language skill. Journal of Educational Psychology, 92(3), Article 466. https://doi.org/10.1037/0022-0663.92.3.466

Fusch, P. I., \& Ness, L. R. (2015). Are we there yet? Data saturation in qualitative research. The Qualitative Report, 20(9), Article 1408. https://doi.org/10.46743/2160-3715/2015.2281

Galobardes, B., Shaw, M., Lawlor, D. A., Lynch, J. W., \& Smith, G. D. (2006). Indicators of socioeconomic position (Part 1). fournal of Epidemiology \& Community Health, 60(1), 7-12. https://doi.org/10.1136/jech.2004.023531

Geiser, C. (2012). Data analysis with Mplus. New York, NY, USA: Guilford Press.

Guilford, J. P. (1954). Psychometric methods. New York, NY, USA: McGraw-Hill.

Gunn, B. K., Simmons, D. C., \& Kameenui, E. J. (1995). Emergent literacy: Synthesis of the research. National Center to Improve the Tools of Educators, College of Education, University of Oregon, Eugene, OR, USA.

Hair, J. F., Jr., Black, W. C., Babin, B. J., \& Anderson, R. E. (2010). Multivariate data analysis: A global perspective. Upper Saddle River, NJ, USA: Pearson Education.

Hart, S. A., Ganley, C. M., \& Purpura, D. J. (2016). Understanding the home math environment and its role in predicting parent report of children's math skills. PLoS One, 11(12), Article e0168227. https://doi.org/10.1371/journal.pone.0168227

Hinkin, T. R. (1998). A brief tutorial on the development of measures for use in survey questionnaires. Organizational Research Methods, 1(1), 104-121. https://doi.org/10.1177/109442819800100106

Hinkin, T. R., \& Schriesheim, C. A. (1989). Development and application of new scales to measure the French and Raven (1959) bases of social power. Fournal of Applied Psychology, 74(4), Article 561. https://doi.org/10.1037/0021-9010.74.4.561

Hobbs, G., \& Vignoles, A. (2007). Is free school meal status a valid proxy for socio-economic status (in schools research)? (No. 84). Centre for the Economics of Education, London School of Economics and Political Science. London, United Kingdom.

Howe, N., Adrien, E., Della Porta, S., Peccia, S., Recchia, H., Osana, H. P., \& Ross, H. (2015). 'Infinity means it goes on forever': Siblings' informal teaching of Mathematics. Infant and Child Development, 25, 137-157. https://doi.org/10.1002/icd.1928

Howe, N., Ross, H. S., \& Recchia, H. (2011). Sibling relations in early and middle childhood. In P. K. Smith \& C. H. Hart (Eds.), The Wiley-Blackwell handbook of childhood social development (2nd ed., pp. 356-372). Chichester, United Kingdom: Blackwell.

Hu, L. T., \& Bentler, P. M. (1999). Cut-off criteria for fit indexes in covariance structure analysis: Conventional criteria versus new alternatives. Structural Equation Modeling: A Multidisciplinary fournal, 6(1), 1-55. https://doi.org/10.1080/10705519909540118

Huntsinger, C. S., Jose, P. E., Larson, S. L., Balsink Krieg, D., \& Shaligram, C. (2000). Mathematics, vocabulary, and reading development in Chinese American and European American children over the primary school years. Fournal of Educational Psychology, 92(4), Article 745. https://doi.org/10.1037/0022-0663.92.4.745 
Huntsinger, C. S., Jose, P. E., Liaw, F. R., \& Ching, W. D. (1997). Cultural differences in early mathematics learning: A comparison of Euro-American, Chinese-American, and Taiwan-Chinese families. International fournal of Behavioral Development, 21(2), 371-388. https://doi.org/10.1080/016502597384929

Huntsinger, C. S., Jose, P. E., \& Luo, Z. (2016). Parental facilitation of early mathematics and reading skills and knowledge through encouragement of home-based activities. Early Childhood Research Quarterly, 37, 1-15. https://doi.org/10.1016/j.ecresq.2016.02.005

Isman, E., Ekéus, C., \& Berggren, V. (2013). Perceptions and experiences of female genital mutilation after immigration to Sweden: An explorative study. Sexual \& Reproductive Healthcare, 4, 93-98. https://doi.org/10.1016/j.srhc.2013.04.004

Isman, E., Mahmoud Warsame, A., Johansson, A., Fried, S., \& Berggren, V. (2013). Midwives' experiences in providing care and counselling to women with female genital mutilation (FGM) related problems. Obstetrics and Gynecology International, 2013, Article 785148. https://doi.org/10.1155/2013/785148

Kenny, D. A. (2015). Measuring model fit. Retrieved from http://davidakenny.net/cm/fit.htm

Kenny, D. A., \& McCoach, D. B. (2003). Effect of the number of variables on measures of fit in structural equation modeling. Structural Equation Modeling, 10(3), 333-351. https://doi.org/10.1207/S15328007SEM1003_1

Kirby, J. R., \& Hogan, B. (2008). Family literacy environment and early literacy development. Exceptionality Education International, 18(3), 112-130. https://doi.org/10.5206/eei.v18i3.7629

Kleemans, T., Peeters, M., Segers, E., \& Verhoeven, L. (2012). Child and home predictors of early numeracy skills in kindergarten. Early Childhood Research Quarterly, 27(3), 471-477. https://doi.org/10.1016/j.ecresq.2011.12.004

LeFevre, J. A., Fast, L., Skwarchuk, S. L., Smith-Chant, B. L., Bisanz, J., Kamawar, D., \& Penner-Wilger, M. (2010). Pathways to mathematics: Longitudinal predictors of performance. Child Development, 81(6), 1753-1767. https://doi.org/10.1111/j.1467-8624.2010.01508.x

LeFevre, J. A., Skwarchuk, S. L., Smith-Chant, B. L., Fast, L., Kamawar, D., \& Bisanz, J. (2009). Home numeracy experiences and children's math performance in the early school years. Canadian fournal of Behavioural Science/Revue canadienne des sciences du comportement, 41(2), Article 55. https://doi.org/10.1037/a0014532

Li, C. H. (2016). Confirmatory factor analysis with ordinal data: Comparing robust maximum likelihood and diagonally weighted least squares. Behavior Research Methods, 48(3), 936-949. https://doi.org/10.3758/s13428-015-0619-7

Lukie, I. K., Skwarchuk, S. L., LeFevre, J. A., \& Sowinski, C. (2014). The role of child interests and collaborative parent-child interactions in fostering numeracy and literacy development in Canadian homes. Early Childhood Education fournal, 42(4), 251-259. https://doi.org/10.1007/s10643-013-0604-7

MacKenzie, S. B., Podsakoff, P. M., \& Fetter, R. (1991). Organizational citizenship behavior and objective productivity as determinants of managerial evaluations of salespersons’ performance. Organizational Behavior and Human Decision Processes, 50(1), $123-150$. https://doi.org/10.1016/0749-5978(91)90037-T

Manolitsis, G., Georgiou, G. K., \& Tziraki, N. (2013). Examining the effects of home literacy and numeracy environment on early reading and math acquisition. Early Childhood Research Quarterly, 28, 692-703. https://doi.org/10.1016/j.ecresq.2013.05.004

Marsh, H. W., Hau, K. T., \& Wen, Z. (2004). In search of golden rules: Comment on hypothesis-testing approaches to setting cutoff values for fit indexes and dangers in overgeneralizing $\mathrm{Hu}$ and Bentler's (1999) findings. Structural Equation Modeling, 11(3), 320-341. https://doi.org/10.1207/s15328007sem1103_2

Melhuish, E. C., Phan, M. B., Sylva, K., Sammons, P., Siraj-Blatchford, I., \& Taggart, B. (2008). Effects of the home learning environment and pre-school center experience upon literacy and numeracy development in early primary school. Fournal of Social Issues, 64(1), 95-114. https://doi.org/10.1111/j.1540-4560.2008.00550.x

Melhuish, E. C., Quinn, L., Sylva, K., Sammons, P., Siraj-Blatchford, I., \& Taggart, B. (2013). Pre-school affects longer term literacy and numeracy: Results from a general population longitudinal study in Northern Ireland. School Effectiveness and School Improvement, 24(2), 234-250. https://doi.org/10.1080/09243453.2012.749796

Mercy, J. A., \& Steelman, L. C. (1982). Familial influence on the intellectual attainment of children. American Sociological Review, 47, 532-542. https://doi.org/10.2307/2095197

Missall, K., Hojnoski, R. L., Caskie, G. I., \& Repasky, P. (2015). Home numeracy environments of pre-schoolers: Examining relations among mathematical activities, parent mathematical beliefs, and early mathematical skills. Early Education and Development, 26(3), 356-376. https://doi.org/10.1080/10409289.2015.968243

Missall, K. N., Hojnoski, R. L., \& Moreano, G. (2017). Parent-child mathematical interactions: Examining self-report and direct observation. Early Child Development and Care, 187(12), 1896-1908. https://doi.org/10.1080/03004430.2016.1193731 
Moon, N., \& Ivins, C. (2004). Parental involvement in children's education. London, United Kingdom: DfES.

Morrison, F. J., Connor, C. M., \& Bachman, H. J. (2005). The transition to school. In S. B. Neuman \& D. K. Dickinson (Eds.), Handbook of early literacy research (Vol. 2, pp. 375-394). New York, NY, USA: The Guilford Press.

Muthen, L. K., \& Muthen, B. O. (1998). Mplus [Computer software]. Los Angeles, CA, USA: Muthén \& Muthén.

Muthén, L. K., \& Muthen, B. O. (2017). Mplus. Los Angeles, CA, USA: Muthen \& Muthen.

Niklas, F., Cohrssen, C., \& Tayler, C. (2016). Home learning environment and concept formation: A family intervention study with kindergarten children. Early Childhood Education fournal, 44(5), 419-427. https://doi.org/10.1007/s10643-015-0726-1

Niklas, F., \& Schneider, W. (2014). Casting the die before the die is cast: The importance of the home numeracy environment for preschool children. European fournal of Psychology of Education, 29(3), 327-345. https://doi.org/10.1007/s10212-013-0201-6

Nunes, T., Pretzlik, U., \& Ilicak, S. (2005). Validation of a parent outcome questionnaire from pediatric cochlear implantation. fournal of Deaf Studies and Deaf Education, 10(4), 330-356. https://doi.org/10.1093/deafed/eni027

OfCom, U. K. (2013). Children and parents: Media use and attitudes report. London, United Kingdom: Office of Communications London.

OfCom, U. K. (2016). Children and parents: Media use and attitudes report. London, United Kingdom: Office of Communications London.

Pomerantz, E. M., Moorman, E. A., \& Litwack, S. D. (2007). The how, whom, and why of parents' involvement in children's academic lives: More is not always better. Review of Educational Research, 77(3), 373-410. https://doi.org/10.3102/003465430305567

Rose, D., \& Pevalin, D. (2010). Volume 3 the national statistics socio-economic classification: (Rebased on the SOC2010) User manual (pp. 1-70). London, United Kingdom: Office for National Statistics.

Sammons, P., Elliot, K., Sylva, K., Melhuish, E. C., Siraj-Blatchford, I., \& Taggart, B. (2004). The impact of pre-school on young children's cognitive attainments at entry to reception. British Educational Research fournal, 30, 691-712. https://doi.org/10.1080/0141192042000234656

Schoenfeldt, L. F. (1984). Psychometric properties of organizational research instruments. In T. S. Bateman \& G. R. Ferris (Eds.), Method \& analysis in organizational research (pp. 68-80). Reston, VA, USA: Reston.

Sénéchal, M., \& LeFevre, J. A. (2002). Parental involvement in the development of children's reading skill: A five-year longitudinal study. Child Development, 73(2), 445-460. https://doi.org/10.1111/1467-8624.00417

Sénéchal, M., LeFevre, J. A., Hudson, E., \& Lawson, E. P. (1996). Knowledge of storybooks as a predictor of young children’s vocabulary. Fournal of Educational Psychology, 88(3), Article 520. https://doi.org/10.1037/0022-0663.88.3.520

Sénéchal, M., LeFevre, J. A., Thomas, E. M., \& Daley, K. E. (1998). Differential effects of home literacy experiences on the development of oral and written language. Reading Research Quarterly, 33(1), 96-116. https://doi.org/10.1598/RRQ.33.1.5

Simon, M. A. (1995). Reconstructing mathematics pedagogy from a constructivist perspective. fournal for Research in Mathematics Education, 26(2), 114-145. https://doi.org/10.2307/749205

Skwarchuk, S. L. (2009). How do parents support pre-schoolers' numeracy learning experiences at home? Early Childhood Education fournal, 37, 189-197. https://doi.org/10.1007/s10643-009-0340-1

Skwarchuk, S. L., \& LeFevre, J. A. (2015). The role of the home environment in children's early numeracy development: A Canadian perspective. In B. Perry, A. MacDonald, \& A. Gervasoni (Eds.), Mathematics and transition to school (pp. 103-117). Singapore: Springer. https://doi.org/10.1007/978-981-287-215-9_7

Skwarchuk, S. L., Sowinski, C., \& LeFevre, J. A. (2014). Formal and informal home learning activities in relation to children's early numeracy and literacy skills: The development of a home numeracy model. Journal of Experimental Child Psychology, 121, 63-84. https://doi.org/10.1016/j.jecp.2013.11.006

Stone, E. F. (1978). Research methods in organizational behavior. Santa Monica, CA, USA: Goodyear Publishing Company.

Sylva, K., Melhuish, E., Sammons, P., Siraj-Blatchford, I., \& Taggart, B. (2004). The effective provision of pre-school education (eppe) project: Findings from pre-school to end of Key Stage 1. Nottingham, United Kingdom: Department for Education and Skills.

Sylva, K., Melhuish, E., Sammons, P., Siraj-Blatchford, I., \& Taggart, B. (2008). Final report from the primary phase: Pre-school, school and family influences on children's development during Key Stage 2 (7-11). Nottingham, United Kingdom: Department for Children, Schools and Families.

Thompson, R. J., Napoli, A. R., \& Purpura, D. J. (2017). Age-related differences in the relation between the home numeracy environment and numeracy skills. Infant and Child Development, 26(5), Article e2019. https://doi.org/10.1002/icd.2019 
Vandermaas-Peeler, M., Boomgarden, E., Finn, L., \& Pittard, C. (2012). Parental support of numeracy during a cooking activity with four-year-olds. International fournal of Early Years Education, 20(1), 78-93. https://doi.org/10.1080/09669760.2012.663237

Watts, T. W., Duncan, G. J., Siegler, R. S., \& Davis-Kean, P. E. (2014). What's past is prologue: Relations between early mathematics knowledge and high school achievement. Educational Researcher, 43(7), 352-360. https://doi.org/10.3102/0013189X14553660

West, A. (2007). Poverty and educational achievement: Why do children from low-income families tend to do less well at school? Benefits, 15(3), 283-297.

Williamson, J. B., Karp, D. A., Dalphin, J. R., \& Gray, P. S. (1982). The research craft: An introduction to social research methods. Boston, MA, USA: Little, Brown.

Wilson, A., Hewitt, G., Matthews, R., Richards, S. H., \& Shepperd, S. (2006). Development and testing of a questionnaire to measure patient satisfaction with intermediate care. BMF Quality \& Safety, 15(5), 314-319. https://doi.org/10.1136/qshc.2005.016642

Zippert, E. L., \& Ramani, G. B. (2016). Parents' estimations of preschoolers' number skills relate to at-home number-related activity engagement. Infant and Child Development, 26(2), Article e1968. https://doi.org/10.1002/icd.1968

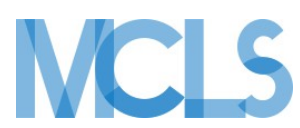

Journal of Numerical Cognition (JNC) is an official journal of the Mathematical Cognition and Learning Society (MCLS).
(P) leibniz-psychology.org

PsychOpen GOLD is a publishing service by Leibniz Institute for Psychology (ZPID), Germany. 